DOI 10.1515/linpo-2016-0012

\title{
The middle as a voice category in Bantu: Setting the stage for further research
}

\author{
Sebastian Dom ${ }^{1}$ \& Leonid Kulikov ${ }^{2}$ \& Koen Bostoen ${ }^{1}$ \\ ${ }^{1}$ Department of Languages and Culture, Ghent University \\ ${ }^{2}$ Adam Mickiewicz University, Poznań \\ e-mail: sebastian.dom@ugent.be, kulikovli@googlemail.com, \\ Koen.Bostoen@ugent.be
}

\begin{abstract}
Sebastian Dom \& Leonid Kulikov \& Koen Bostoen. The middle as a voice category in Bantu: Setting the stage for further research. The Poznan Society for the Advancement of Arts and Sciences, PL ISSN 0079-4740, pp. 129-149

The main goal of our paper is to give a first, general description of middle voice in Bantu. As will be shown, this language group has a set of verbal derivational morphemes that challenges some of the concepts related to the middle domain. First of all, as of yet no description has been found of a language having more than one middle marker, yet many Bantu languages have up to four or five derivational morphemes that cover several parts of the semantic domain of the middle. Secondly, provided that the polysemy patterns of these morphemes only partially cover what is generally considered the "canonical" middle domain, we will call these "quasi-middle" markers. The fact that these verbal morphemes also convey notions that are usually not considered to belong to the domain of the canonical middle calls for a reassessment of what constitutes the semantic core of this voice category cross-linguistically. Although the theoretical implications of these new data are not the central focus of our paper, the basic description that we aim to provide of the middle in Bantu can nevertheless contribute to further discussion on this intricate voice category.
\end{abstract}

Keywords: Bantu, intransitivization, middle voice, quasi-middle, verbal morphology

\section{Introduction}

The middle voice is well-known to be a complex and sometimes messy linguistic category (Shibatani 2004: 1149). Although it has been described for a number of both ancient Indo-European (such as Greek, Sanskrit or Hittite; see, e.g., Jasanoff 1978; Allan 2003) and non-Indo-European languages (among many others, cf. Culy \& Fagan 2001; Palancar 2004; Nagaya 2009), it has proven difficult, if not impossible, to establish a coherent set of core properties and to identify middle voice as a cross-linguistically and typologically valid concept (Kazenin 2001: 923). For our comparative and typologically-oriented Bantu research, we employ a working definition of the middle as a verbal category regularly encoded by means of verbal morphology (e.g. verbal suffix, type of 
inflection etc., typically called "middle marker(s)" in the grammars of the corresponding languages; see Kemmer 1993: 15) that is used to encode a variety of closely related functions which (i) belong to the domain of voices and voice-related categories, (ii) focus the activity expressed by the base (most often, transitive) verb on one single argument, and (iii) syntactically, amount to intransitivization of the base verb. In most languages where the grammatical tradition posits the category of the middle, the functions of the middle marker include the reflexive, the passive, the anticausative, the antipassive, and the reciprocal (which can be considered as the functional core of this category) as well as, very often, a few other related functions, such as autobenefactive or impersonal. Accordingly, the content of the category of middle can be considered as a cluster of both semantically and syntactically closely-related (usually associated with intransitivization) functions (see Kulikov 2013: 265-266). In the event when a verbal marker is used to encode more than one (two or three) functions of the middle domain, which do not however encompass the major part of the middle domain, we will use the working term 'quasi-middle'.

The main goal of our paper is to give a first, general description of middle voice in Bantu. The middle as a distinct voice category has never been the subject of systematic research in Bantu linguistics. This is largely due to the fact that Bantu languages do not have one single verbal suffix expressing the manifold grammatical functions and lexical categories subsumed under middle voice. Rather, as we will show here, many Bantu languages make use of multiple derivational morphemes that denote only a part of the functions of the canonical middle domain. Although the properties of these verbal suffixes largely correspond to the four components of our definition of the middle, as we show in this article, the range of their functions never spans the entire middle domain. We therefore label them 'quasi-middles'. From a historical point of view, they might also be called 'proto-middles' in the sense that they could develop into canonical middles (cf. Grestenberger 2016: 138 et passim for a discussion of the Proto-Indo-European non-canonical middle, presumably a proto-middle).

In the typological literature, Bantu language data have either been neglected in discussions on the middle voice, or, still more regrettably, misinterpreted. In particular, Kemmer (1993: 26) categorizes the Bantu languages Changana and Pangwa as languages with a one-form middle system. This would mean that these languages have a single middle marker which is also used to denote reflexivity. However, as the overview in (1), which presents some of the examples cited by Kemmer (1993), shows, Changana does not have one, but (at least) two verbal morphemes that denote middle situation types.

a. Reflexive/middle $-t i$ -

$\begin{array}{lll}\text { ku ti-tekela } & \text { 'take for oneself' (p. 17) } & \text { [indirect middle/autobenefactive] } \\ \text { ku ti-milela } & \text { 'germinate, sprout' (p. 19) } & \text { [spontaneous event] } \\ \text { ku ti-tsakela } & \text { 'be(come) happy' (p. 21) } & \text { [emotive middle] } \\ \text { ku ti-nwaya } & \text { 'scratch, rub oneself' (p. 61) } & \text { [bodily action middle] }\end{array}$

b. Reciprocal/middle $-a-^{1}$

ku ring-an- $a$ 'be(come) similar' (p. 107)

[naturally reciprocal event]

${ }^{1}$ In correspondence with common practice in Bantu linguistics, we reparsed what Kemmer considers to be the ending $\boldsymbol{- n} \boldsymbol{a}$ as the verb root extension $\boldsymbol{- a n}$-, which is followed by the default final vowel $\boldsymbol{- a}$. 
ku hamb-an-a 'be separate, different' (p. 107)

$k u$ thlang-an- $a$ 'reunite, be reunited' (p. 107) [naturally reciprocal event]

[sociative middle]

Bantu languages have a rich set of verbal affixes, which are used for a diverse range of functions, such as co-reference of core arguments, tense-aspect-mood-negation, information structure, and certain types of verbal derivation (Bearth 2003; Schadeberg 2003; Nurse 2008). Derivational suffixes immediately follow the verb root and are therefore also called 'extensions'. They are a typical feature of the Bantu verbal system. Several of those that are still found in present-day Bantu languages have been reconstructed to Proto-Bantu (Meeussen 1967: 92). As can be seen in (2), most suffixes have a -VC- shape (Schadeberg 2003: 72). The common Bantu reflexive marker, reconstructed in Proto-Bantu as $*_{-}(j) i$ - (Meeussen 1967: 109-110), is to be distinguished from the derivational root extensions in that it is a prefix occurring in the verb morpheme slot that is reserved for object markers (Marlo 2015). The names of these morphemes are adopted from Schadeberg (2003).

(2) List of Proto-Bantu reconstructions of derivational morphemes

$\begin{array}{ll}*_{-}(j) i- & \text { reflexive } \\ *_{-i-/-i c i} & \text { causative } \\ *_{-I l-} & \text { applicative } \\ *_{-I k-} & \text { impositive } \\ *_{-I} \boldsymbol{k}- & \text { neuter } \\ *_{-a m-} & \text { positional (stative) } \\ *_{-a n-} & \text { associative (reciprocal) } \\ *_{-a g-} \sim-a n g- & \text { repetitive } \\ *_{-a l-} & \text { extensive } \\ *_{-a t-} & \text { tentive (contactive) } \\ *_{-\mho--;-\sigma k-} & \text { separative tr.; intr. (reversive) } \\ *_{-\mho-/-i b v-} & \text { passive }\end{array}$

In this paper, we discuss the middle status of the present-day reflexes of the five Proto-Bantu derivational morphemes marked in bold (\$2). Although the semantics of

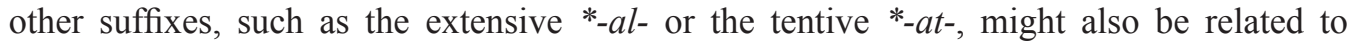
the middle domain, we discuss here those verbal suffixes for which the literature is vast enough to give a comparative and historical discussion. In $\S 2$, we provide an overview of the functions encoded by these morphemes: the neuter suffix $*_{-I} k-(\$ 2.1)$, the positional suffix *-am- $(\S 2.2)$, the associative suffix *an- $(\S 2.3)$, the separative intransitive

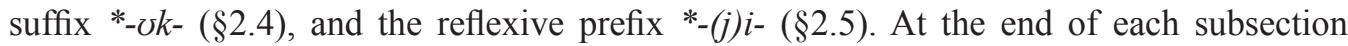
a semantic map, based on Kemmer (1993), is provided showing the overlap between the canonical middle domain and the functions of the particular derivational morpheme. The typological implications of languages with multiple (quasi-)middle markers are sketched in $\S 3$. Finally, conclusions will be presented in $\S 4$. For the most part, data stem from either published (Bostoen et al. 2015) or unpublished (Bostoen 2010, Dom 2015) studies, or come from on-going research.

An important caveat to the general character of our description is that it is not our intention to classify these suffixes as quasi-middles in all Bantu languages. For each and every individual language, the four properties of our working definition of the middle 
voice have to be checked. We would only suggest considering a particular affix as a quasi-middle marker in a particular language, if in that language it exhibits a polysemy including two or more middle categories. With this study we provide important evidence for a typological research on the category of quasi-middle.

\section{Middle status of Bantu derivational suffixes}

\subsection{The neuter suffix $*_{-I} k$ -}

The neuter suffix is used in three types of constructions, of which the first type can be defined as derivations in which the corresponding object of the active clause is promoted to subject position, and the corresponding subject is demoted to an oblique position or omitted. This first type includes anticausative (3), agentless passive (4) and passive (5) constructions.

(3) Bena (Tanzania) (Morrison 2011: 368)
a. u-mu-ana a-haa-deeny-ile
$\mathrm{AUG}_{1}-\mathrm{CL}_{1}$-child $\mathrm{SM}_{1}$-PST-break-FV
'The child broke the twig yesterday.' u-tu-bihi igólo. ${ }^{2}$
b. u-tu-bihi tu-haa-deeny-ih-ile
$\mathrm{AUG}_{13}-\mathrm{CL}_{13}$-tree $\mathrm{SM}_{13}$-PST-break-NT-FV yesterday
igolo
$\mathrm{AUG}_{13}-\mathrm{CL}_{13}$-tree yesterday
'The twig broke yesterday.'

(4) Chewa (Malawi) (Dubinsky \& Simango 1996: 751)

m-bale zi-na-tsuk-ik-a (*ndi Naphiri).

$\mathrm{CL}_{10}$-plate $\mathrm{SM}_{10}$-PST-wash-NT-FV by Naphiri

'The plates were washed (*by Naphiri).'

(5) Tumbuka (Malawi) (Chavula 2016: 65)
n-duna
zi-ka-cem-ek-a
na Chikulamayembe.
$\mathrm{CL}_{10}$-minister $\mathrm{SM}_{10}$-PST-call-NT-FV by Chikulamayembe

'The ministers were called for by Chikulamayembe.'

These three derivations can usually, though not always, be clearly distinguished from each other. The anticausative alternation is typically restricted to the class of verbs that allow for both an agentive-transitive and a spontaneous-intransitive argument construction. Typically, the latter does not allow for oblique agentive phrases ('passive agent') and, moreover, lacks the agent role in its semantic structure, thus differing from the syntactically similar but semantically distinct agentless passive. By contrast, the (canonical) passive construction necessarily implies the presence of a passive agent, as shown for Ndebele in (6).

\footnotetext{
${ }^{2}$ We have unified the various glosses of different authors into a consistent system.
} 
(6)
Ndebele (Zimbabwe) (Khumalo 2009: 168)
a. isi-valo s-a-val-ek-a
(*ngu Thabo).
$\mathrm{CL}_{7}$-door $\mathrm{SM}_{7}$-PST-shut-NT-FV by Thabo
'The door closed (*by Thabo).'
b. isi-valo $s$-a-val-w-a (ngu Thabo).
$\mathrm{CL}_{7}$-door $\mathrm{SM}_{7}$-PST-shut-PASS-FV by Thabo
'The door was closed (by Thabo).'

The agentless passive construction combines features of the anticausative and passive. On the one hand, its argument structure is identical to that of the anticausative in that the patient is in subject position and the agent cannot be expressed, although it is still semantically implied (Kulikov 2011: 230-232). The latter thus also cannot be introduced in an oblique phrase. On the other hand, the semantics of the derived verbs do not allow for a spontaneous-intransitive reading, which differentiates it from the anticausative and makes it more like a passive construction. Such is the case in example (4) above, where a reading of the plates having washed themselves seems improbable, if not impossible in a real-world, non-magical interpretation. However, just as with the anticausative construction, agentive noun phrases make the sentence ungrammatical (cf. (4) above). Only in the event that the constraint of the lack of the agent/agentive noun becomes optional, does the functional range of the neuter morpheme expand so as to include passive proper. To our knowledge, the only Bantu language where this change has been reported so far is Tumbuka, illustrated above in (5). There is interesting syntactic variation across Bantu with regard to how extended neuter verbs pattern with oblique and instrumental phrases, adverbs, or purpose clauses. Due to space constraints, we cannot discuss such differences here, but we refer the reader to Dom (2014, 2015: 10-16).

The second type of constructions marked by the neuter suffix are patient-oriented potentials. In these constructions, the subject is typically a patient-like participant to which a quality, denoted by the verb, is attributed. To this type belong potential passives (7) and facilitatives (8).

(7) Swahili (Tanzania) (Seidl \& Dimitriadis 2002: 254)

Ø-godoro li-na-lal-ik-a.

$\mathrm{CL}_{5}$-mattress $\mathrm{SM}_{5}$-PRS-sleep-NT-FV

'This mattress can be slept on.'

(8) Tswana (Botswana; South-Africa) (Creissels 2002: 403)

Mae a thubega motlhofo.

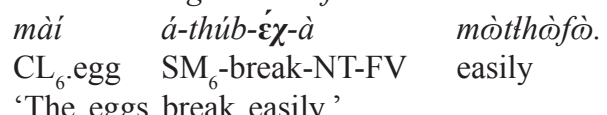

'The eggs break easily.'

As shown in (7), this type of constructions differs from the previous in terms of transitivity. Intransitive verbs, such as Swahili kulala 'sleep', can be derived by the neuter with a potential passive reading, whereas anticausative and (agentless) passive constructions can only be derived from transitive verbs. Moreover, although in (8) the verb allows an anticausative derivation, the potential passive reading is construed through the 
use of specific (non-completive, non-past) TAM inflections and the manner adverb

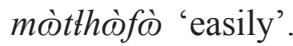

The third and last type of constructions are restricted to perception verbs. The experiencer is typically demoted or omitted and the subject position is either occupied by a promoted stimulus participant or a covert generic participant. This last type includes stimulus (9) and evidential (10) constructions.

(9) Ganda (Uganda) (UGent Luganda Corpus compiled and queried by Deo Kawalya)

[...] birabiké búlúngi nga bitereddé.

bi-lab-ik-e bu-lungi nga bi-tereer-e.

$\mathrm{SM}_{8}$-see-NT-SBJV $\mathrm{CL}_{14}$-nice like $\mathrm{SM}_{8}$-be_in_order-SBJV

'[...] so that they look nice as if they are in order.'

(10) Luragooli (Kenia; Tanzania) (Bowler \& Gluckman 2016: 3)

a. Indirect evidentiality (hearsay)

$\begin{array}{lllll}\underline{e} \text {-hol-ek- } a^{3} & \text { kuresa } & v u \text {-geni } & v u \text {-ar- } \varepsilon & \text { vu-hare } \\ \mathrm{SM}_{9} \text {-hear-NT-FV } & \text { like } & \mathrm{CL}_{14} \text {-party } & \mathrm{CL}_{14} \text {-COP-FV } & \mathrm{CL}_{14} \text {-good }\end{array}$

'It sounds like the party was fun.'

b. Direct evidentiality (auditory)

$\begin{array}{lllll}\text { ga-hol-ek-a } & \text { kuresa } & \text { vu-geni } & v u \text {-ar- } \varepsilon & \text { vu-hare } \\ \text { SM }_{6} \text {-hear-NT-FV } & \text { like } & \mathrm{CL}_{14} \text {-party } & \mathrm{CL}_{14} \text {-COP-FV } & \mathrm{CL}_{14} \text {-good }\end{array}$

'It sounds like the party was fun.'

(10a) and (10b) differ in evidentiality (indirect vs. direct). The former is conveyed, on the one hand, by using the subject marker of class 9 on the derived perception verb. This would, for example, be uttered by a speaker who has been told that the party was good. Direct evidentiality, on the other hand, is expressed through the use of the class 6 subject marker, i.e. (10b) would be uttered by someone who overheard a loud party in a room next to him.

Having outlined the three types of constructions in which the neuter is used, it is evident that this suffix is not a prototypical middle marker. Its locus in the middle domain spans only patient-oriented constructions, and a number of its functions, such as potential passive, stative, stimulus and evidentiality, are generally not considered as subcategories of the middle voice. This is shown in Figure 1, where the cross-Bantu semantic range of neuter $*_{-I} k$ - is plotted on a semantic map of the middle domain as proposed in Kemmer (1993: 202) with some minor modifications. Nevertheless, in many Bantu languages, neuter *-I $k$ - does conform to the definition of the middle morpheme as encoding a "cluster of deagentivized (intransitivized) syntactic patterns" (Kulikov 2013: 265) that focus the activity expressed by the base verb on one single argument (subject).

\footnotetext{
3 Perception verbs derived by the neuter are not the only possible predicates of evidential constructions in Luragooli. There is the underived verb kufana 'to seem' or the passive kusoverwa 'to be believed', and cognition and speech verbs, nevertheless derived by the neuter, such as kumanyeka 'to be known' and kuvoleka 'to be said' (Bowler \& Gluckman 2016).
} 


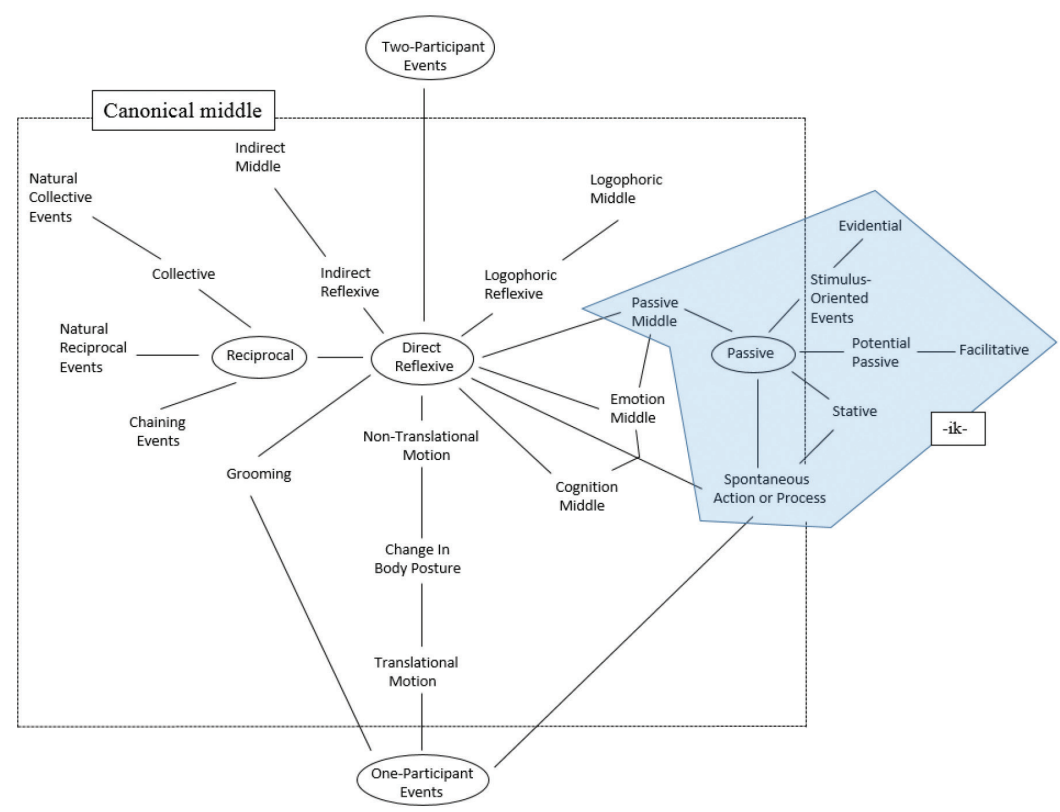

Figure 1. The cross-Bantu semantic range of neuter $*-I k$ - plotted on the semantic map of the middle domain (cf. Kemmer 1993)

\subsection{The positional suffix $*_{-a m-}$}

In most Bantu languages, this suffix does not affect the argument structure of the verb. Rather, as Schadeberg (2003: 75) writes, "the common element of meaning is 'assuming a position', or - when used in a perfective aspect form - 'to be in a position"”. According to this definition, the semantic value of this morpheme is closely related to middle situation types of non-translational motion and change in body posture (Kemmer 1993: 55-56). However, the semantic range of common Bantu verbs extended with -amindicates that it is considerably larger than just 'positional', as the Bantu lexical reconstructions from Bastin et al. (2002) in (11) show. ${ }^{4}$

\section{(11) Positional \\ *-bátam- 'be flat or level'; 'lie flat' \\ *-dìdam- 'be straight' \\ *-bókam- 'sit'}

${ }^{4}$ As one reviewer noted, the roots of these Proto-Bantu verbs having the *-am- extension are not reconstructed without this suffix. They are deponents in the sense of Kemmer (1993:22), viz. "[middle marked] verbs [that] lack unmarked counterparts." We nevertheless analyze these verbs as [root+suffix] on the basis of the formal criteria that in Bantu verb roots have the morphophonological structure -CV(NC)-, and that any verb base with a longer morphophonological structure includes derivational morphology (Schadeberg 2003: 71-72). 


\section{Spontaneous/stative}

*-pákam- 'be jammed', 'be wedged'

*-comam- 'be inserted', 'put in'

*-bòmbam- 'be wet'

\section{Non-translational motion}

*-jìnam- 'bend over'

*jácam- 'open the mouth'; 'yawn'

*-pàpam- 'flap wings', 'flutter'

\section{Emotion}

*-bòngam- 'be sad'

*-crnam- 'be in a bad mood'

*-dápam- 'be greedy in eating'

\section{Translational motion}

*-dòngam- 'go straight'

*-búgam- 'paddle'

*-tèntam- 'go at the top of'

\section{Cognition}

*-dúdam- 'forget'

Interestingly, in several Bantu languages, especially those spoken in the vicinity of the Middle and Lower Congo River, the positional suffix has become the canonical passive marker (Grégoire 2003: 365; Schadeberg 2003: 76), as in the Lingala example in (12). A similar shift has been observed in vehicular Kikongo (Fehderau 1962), also known as Kikongo ya Leta, Kituba or Monokutuba (13), as well as in certain vernacular Kikongo varieties (Kisilu Meso 2001: 32; Kouarata 2015: 89).

(12) Lingala (DR Congo; Republic of the Congo) (Meeuwis 2010: 155-156)

mbóngo e-bómb-ám-áki na moyibi.

money SM $_{3 \mathrm{SG} . \mathrm{INAN}}$-hide-PASS-PST by thief

'The money was hidden by the thief.'

(13) Kituba (DR Congo; Republic of the Congo) (Fehderau 1962: 72)
mu-kanda
$\varnothing$-me-tang-am- $a$
na m-pangi
na mono
$\mathrm{CL}_{3}$-book
$\mathrm{SM}_{3}$-PST-read-PASS-FV
by
$\mathrm{CL}_{9}$-brothe
of me

'The book was read by my brother.'

The list of verbs in (14) illustrate that in these languages the positional both occurs with verbs denoting middle situation types and encodes passive derivation.

(14) Mongo (DR Congo) (Hulstaert 1957, 1965: 247-250)

\section{Middle}

-kákema 'hang up (intr.)'

${ }^{5}$ When -am- immediately follows a verb root with vowel [a], the suffix is realized as -em-, or in case of a root with vowel $[\varepsilon]$ it's realized as $-\varepsilon m$-. In all other cases the suffix is realized in its underlying form (Hulstaert 1965: 247). 
-kólama '(be) strand(ed), get stuck'

-kəfama 'hang (oneself)'

-kukama 'be attached/stuck against (sth.)'

-télema 'stand up/be standing'

\section{Passive}

\begin{tabular}{|c|c|c|c|}
\hline -laka & 'teach' & -lakema & 'be taught' \\
\hline -lela & 'want, desire' & -lelama & 'be desired, wanted' \\
\hline -sála & 'cut' & -sálema & 'be cut’' \\
\hline -sana & 'play (sth.)' & -sanema & 'be played' \\
\hline -tómba & 'carry' & -tómbama & 'be carried' \\
\hline
\end{tabular}

In Figure 2, the semantic range of the positional $*$-am- is projected on the map of the canonical middle domain. Compared to the neuter suffix $*_{-I} k$-, the positional seems to have much fewer semantic outliers (i.e., only one) and covers more middle situation types.

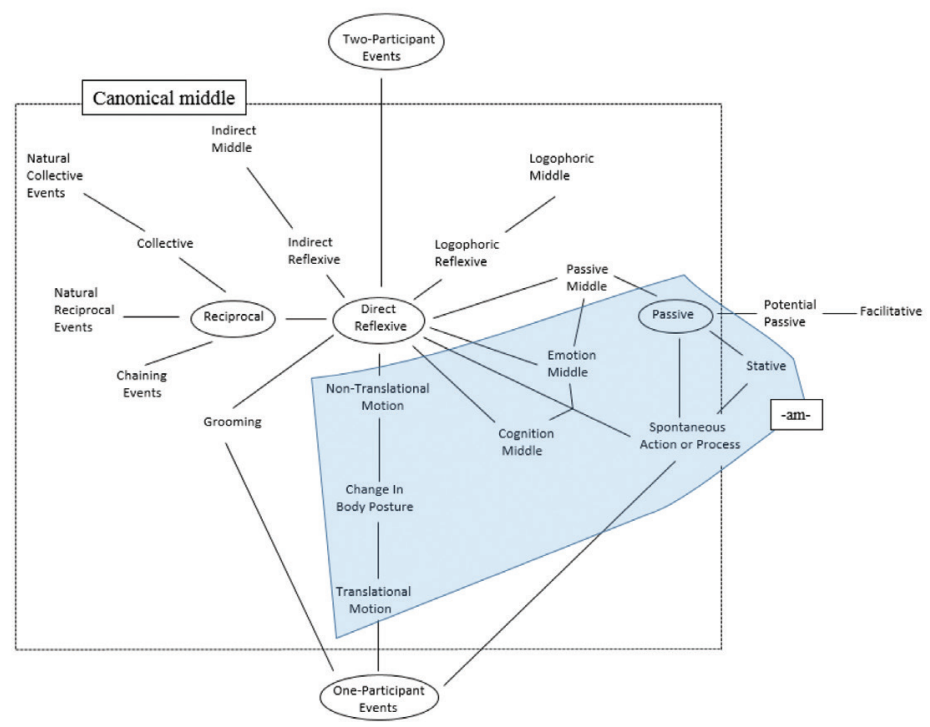

Figure 2. The cross-Bantu semantic range of positional $*$-am-plotted on the semantic map of the middle domain (cf. Kemmer 1993)

\subsection{The associative suffix *an-}

Reflexes of the associative suffix *an- encode in Bantu languages what is more generally known as sociative and reciprocal derivation (Nedjalkov 2007a). This extension is notoriously polysemous. Bostoen et al. (2015) give an extensive, cross-Bantu overview of its varied uses. They include the fourteen grammatical categories and lexical classes listed in (15). 
a. Grammatical categories

antipassive

comitative

intensive/extensive

iterative

mediopassive

potential

reciprocal

sociative/collective b. Lexical classes

body action events

chaining events

cognition events

natural collective events

natural reciprocal events

spontaneous events

Even though this high polysemy is remarkable per se, some functions still spark more interest than others, if one acknowledges that sociativity/reciprocity constitutes the semantic core of this morpheme. The main goal of Bostoen et al. (2015) is to give antipassive voice recognition in Bantu linguistics, which was often neglected or referred to with idiosyncratic terminology in descriptions of individual languages. From a typological perspective, however, the diachronic path in which reciprocal markers extend their usage to include antipassive function is not uncommon cross-linguistically (Nedjalkov 2007b: §9.2; Janic 2016: §7.4), and thus well-known among general linguists. As illustrated in (16), Rundi is a Bantu language where associative -an-also marks the antipassive.

(16) Rundi (Burundi) (Bostoen et al. 2015: 736)

a-ma-hwá a-ra-zibur-an-a

$\mathrm{AUG}_{6}-\mathrm{CL}_{6}$-thorn $\quad \mathrm{SM}_{6}$-PRS.DISJ-prick-ASS-FV

'Thorns prick (people).'

Generally speaking, the polysemy of associative -an- can be semantically accounted for through the cross-linguistically common concept of 'plurality of relations' (Lichtenberk 2000; Janic \& Segerer 2011; Bostoen et al. 2015: §3.5). In some languages, however, the associative has acquired functions that cannot be explained in this way. It can be used as a comitative suffix introducing an instrumental participant, such as mondó 'tail' in the Duala example in (17). In Bantu, instrument-like participants are generally rendered by prepositional phrases. In example (18a) from Rwanda, the comitative function of associative -an- promotes the manner NP ûmweête 'enthusiasm' as a direct object, although the common strategy with the comitative preposition $n a$ is also still available as in (18b).

(17) Duala (Cameroon) (Helmlinger 1972: 399)

náka e-ma-bol-an- $\varepsilon \quad$ mondo

$\mathrm{CL}_{9}$.cow $\mathrm{SM}_{9}$-PRS-do-ASS-FV $\mathrm{CL}_{3}$.tail to chase-ASS-FV $\mathrm{CL}_{10}$. mosquito

'The cow uses its tail to chase away mosquitos.'

(18) Rwanda (Rwanda) (Kimenyi 1988: 369)

a. Associative as instrumental marker

u-mu-góre a-rá-kôr-an-a

akazi u-mw-eête

$\mathrm{AUG}_{1}-\mathrm{CL}_{1}$-woman $\quad \mathrm{SM}_{1}$-PRS-work-ASS-FV

work $\mathrm{AUG}_{3}-\mathrm{CL}_{3}$-enthusiasm

'The woman is working with enthusiasm.' 
b. Instrumental preposition $n a$

$\begin{array}{lllll}\text { u-mu-góre } & a-r a ́-k o ̂ r-a & a k a z i & n^{\prime} & \hat{u} \text {-mw-eête } \\ \mathrm{AUG}_{1}-\mathrm{CL}_{1} \text {-woman } & \mathrm{SM}_{1} \text {-PRS-work-FV } & \text { work } & \text { with } & \mathrm{AUG}_{3}-\mathrm{CL}_{3} \text {-enthusiasm }\end{array}$

'The woman is working with enthusiasm.'

More relevant to our discussion on the middle voice are Bantu languages in which associative -an- marks a number of middle situation types. Again, some of these have close connections to its core meaning of sociativity/reciprocity, such as natural reciprocal, sociative and chaining events. However, it is also found with middle meanings that are further removed from its semantic core, such as body action, cognition and spontaneous events. These different middle situation types are illustrated for various Bantu languages in (19) and (20).

(19) Verbs denoting middle situation types marked by the associative

a. Natural reciprocal and sociative events in Luba-Kasai (DR Congo) (Kabuta 2008)

$\begin{array}{ll}\text {-fwàngana } & \text { 'discuss' (p. 107) } \\ \text {-fwàna } & \text { 'resemble' (p. 107) } \\ \text {-pùukana } & \text { 'find, meet, bump against; succeed' (p. 285) } \\ \text {-sangana } & \text { 'find, meet' (p. 291) }\end{array}$

b. Body action and cognition/emotion events in Fang (Gabon) (Bostoen and Nzang-Bie 2010: 1279-1280)

-tsim- $\boldsymbol{a}^{6} \quad$ 'wipe one's arse'

-fol-a 'change oneself, change clothes'

-wúr-á 'huddle up, flinch, wince'

-kor-a 'fold (arms, hands), cross (legs)'

-yá-á 'get angry'

-zob-a 'regret, be embarrassed by unpleasant news, be sad'

-sim-á 'remember, think'

c. Spontaneous/stative events in Orungu (Gabon) (Ambouroue 2007: 188)

-ßúrànà 'bend (intr.)'

-ßàndyànà 'scatter (intr.)'

-yìrànà 'flow'

-wòndyàna 'get wounded'

(20) Lingala (DR Congo, Republic of the Congo) (Bostoen et al. 2015: 750)

mí-tuka misátu e-tút-án-í

$\mathrm{CL}_{4}$-car three $\mathrm{SM}_{3 \mathrm{PL} . \mathrm{INAN}}$-hit-ASS-PRF

'Three cars have bumped into one another.'

In contrast to the neuter, the semantic space of the associative is mainly centred on agent-oriented constructions and situation types, as is shown in Figure 3. For reasons of representation, the demarcation of what constitutes the semantic space of the canonical middle has been modified to facilitate the comparison to the semantic space of the associative.

${ }^{6}$ In this language the reflex of Proto-Bantu *an- is the suffix $-a$. 


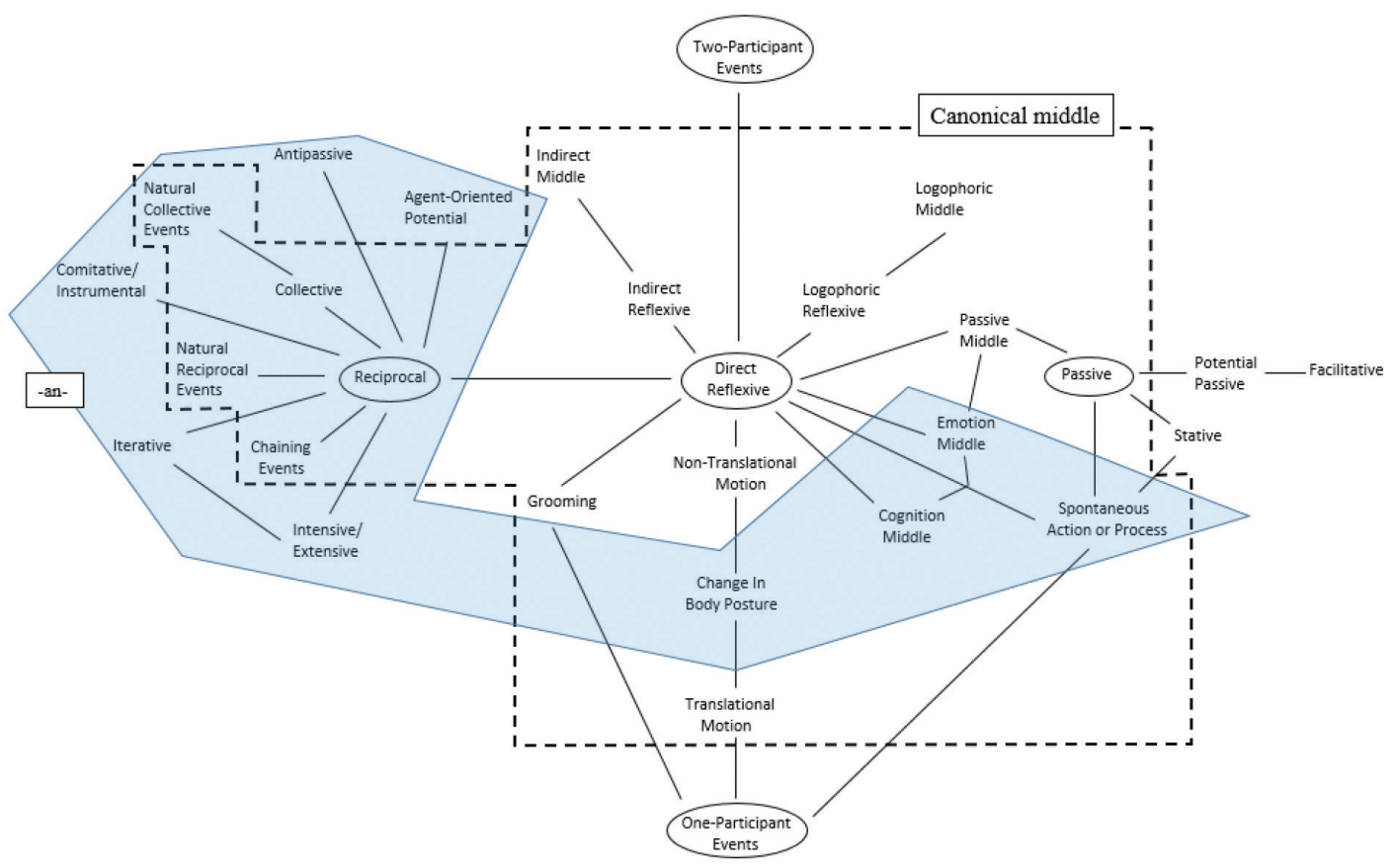

Figure 3. The cross-Bantu semantic range of associative *-an-plotted on the semantic map of the middle domain (cf. Kemmer 1993)

\subsection{The separative intransitive suffix}

The Proto-Bantu separative suffixes $*_{-} \sigma d$ - and $*_{-}-k$ - have reflexes throughout the Bantu domain. Schadeberg $(1982,2003)$ reconstructs 'movement out of some original position' as their core meaning. As is the case for positional -am-, the derivational function of this suffix pair is semantic rather than syntactic in nature. In terms of valency-changing effects, they are in complementary distribution: reflexes of $*_{-\mho \sigma d-\text { generally }}$ mark transitive verbs, while reflexes of $*-v k$ - commonly mark intransitive verbs. As is shown for Swahili in (21), not every verb root is necessarily found with both suffixes. Moreover, the base verb is often no longer attested in present-day Bantu languages and can sometimes even not be reconstructed.

(21) Swahili (Tanzania) (Racine 2015: 42, 49, 55)

$$
\begin{aligned}
& \text { TRANSITIVE INTRANSITIVE } \\
& \text {-bag-u-a 'separate, divide' -bag-uk-a 'be separated, divided' } \\
& \text {-nas-u-a 'set free from a trap' / } \\
& \text { / } \quad-f-o k-a \text { 'spill over' }
\end{aligned}
$$

Here we focus only on the intransitive suffix, whose Proto-Bantu reconstructions, as listed by Schadeberg (1982), can all be classified into middle situation types (22). 
(22) Classification of Proto-Bantu *-vk- verbs from Schadeberg (1982: 61-65) into middle situation types

a. ((Non-)Translational) Motion

*-jíbzk- 'come out of water'

*-jinzk- 'straighten oneself, go home from work'

*-jínøk- 'come out of water'

*-jídvk- 'run'

*-kidvk- 'jump over'

*-kébøk- 'look around/behind'

*-jèpwk- 'avoid, get out of the way'

*-tázk- 'come out/from'

*jàbzk- 'cross river'

*-gàdซk- 'come/go back'

*-cómok- 'come out'

*-kòtzk- 'go home from work'

*-kùvk- 'come out'

*-gơdvk- 'fly'

*-púdvk- 'escape'

*-túvdøk- 'come/go down'

*-bútok- 'run'

*-bútzk- 'come/go back'

b. Change in body posture

*-jím $\boldsymbol{k}$ - 'stand up'

*-pì(n)dvk- 'turn over, alter (intr.)' (also spontaneous event)

*-támbøk- 'walk, travel'

c. Spontaneous event

*-dizk- 'revive (intr.)'

*-titimøk- 'be startled, wake up'

*-jitzk- 'startled'

*-cèdok- 'boil up, froth up'

*-pépvk- 'light in weight, get blown away' (also stative)

*-dàmøk- 'wake up (intr.)'

*-kámøk- 'dry up (intr.)'

*-jàmbzk- 'spread (as a disease or fire)'

*-bábvk- 'singe (intr.)'

*-badvk- 'split (intr.)'

*-gàd $\boldsymbol{k}$ - 'turn, alter'

*-jápzk- 'separate, split (intr.)'

*-játzk- 'split (intr.)'

*-mónyzk- 'break off (intr.)'

*-tútomøk- 'boil up/over'

*-tưmbzk- 'burst open'

*-cùbok- 'have a rash'

*-dúzk- 'fall off (of clothes)' d. Cognitive

*-jibzk-/-jijok- 'remember'

*-kن́mbwk- 'remember'

e. Stative

*-dédvk- 'be light'

*-cóngwk- 'be sharp, pointed'

*-godvk- 'be straight'

*-cóvk- 'be ugly'

In Cuwabo (Mozambique), the separative intransitive is still used to mark different middle situation types, such as change in body posture (23), translational motion (24), emotion events (25), and spontaneous processes (26). 
(23)

$\begin{array}{llll}\text { a-zugúnúw-á } & a \text {-dh-á } & \text { a-malríh-a } & \text { dhi-ója } \\ \mathrm{SM}_{1} \text {-turn_round-FV.SEQ } & \mathrm{SM}_{1} \text {-come-FV.SEQ } & \mathrm{SM}_{1} \text {-finish-FV.SEQ } & \mathrm{CL}_{10} \text {-food }\end{array}$ a-já a-eká

$\mathrm{SM}_{2}$-eat-FV.SEQ $\quad \mathrm{CL}_{2}$-alone

'He (the cat) turned round, came to finish the food alone'

(Guérois 2015: 684)
o-hí-búddúw-a
mú-nddímúwa
mwáná-kálâba
$\mathrm{SM}_{1}$-PFV.DISJ-go_out-FV
$\mathrm{CL}_{1}$-old_man
$\mathrm{CL}_{1}$. child- $\mathrm{CL}_{1 \mathrm{a}}$. senior

'An old man came out.'

(Guérois 2015: 613)
ábále
ddabunó
a-oté=éne
a-hi-jíbúluw-a
$\mathrm{CL}_{2}$. DEM ${ }_{\mathrm{III}}$ then $\quad \mathrm{CL}_{2}$-all=INT $\mathrm{SM}_{2}$-PFV.DISJ-get_upset-FV

'All those around got upset.'

(Guérois 2015: 624)
á-yíma ábá
a-hí-únúw-a
va-ñgónó va-ñgónó
$\mathrm{CL}_{2}$-child $\mathrm{CL}_{2}$.DEM $\mathrm{DM}_{2}$-PFV.DISJ-grow-FV $\mathrm{CL}_{16}$-little $\mathrm{CL}_{16}$-little
'These children grew up little by little.'
(Guérois 2015: 607)

Interestingly, the separative intransitive suffix has undergone a similar functional expansion in Cuwabo as the reflex of positional *am- in several languages in the northwestern part of the Bantu domain (cf. §2.2). In this language it has become a passive marker, although in free variation with the regular reflex - $i w$ - of the canonical Proto-Bantu passive suffix *-ibv- (Guérois \& Bostoen 2016). Both passive markers allow the agent to be introduced by an oblique prepositional phrase (27).

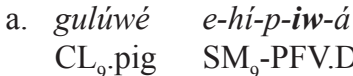
na mú-lóbwana
$\mathrm{CL}_{9}$.pig $\mathrm{SM}_{9}$-PFV.DISJ-kill-PASS-FV by $\mathrm{CL}_{1}$-man
'The pig was killed by the man.'
(Guérois \& Bostoen 2016: 2)
b. míri dhí-ni-ó-j-uw-á
na nyenyéle
$\mathrm{CL}_{4}$-tree $\mathrm{SM}_{4}$-IPFV.DISJ-CL 15 -eat-PASS-FV by $\mathrm{CL}_{10 \mathrm{a}}$.ant
'The trees are being eaten by the ants.'
(Guérois 2015: 339)

As far as we know, Cuwabo is the only language where this specific expansion of the separative intransitive from marking middle situation types to a canonical passive marker has taken place. With many Bantu languages still remaining un(der)described, future research might lead to the discovery of other languages where this development is attested.

As shown in Figure 4, apart from the canonical passive, only reported to be associated with the reflex of *-vk- in Cuwabo, the separative intransitive suffix most commonly occurs with a wide range of verbs denoting middle situation types, which are actual-

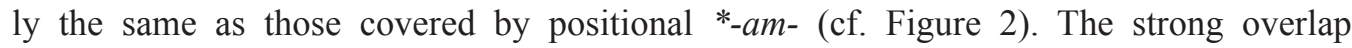




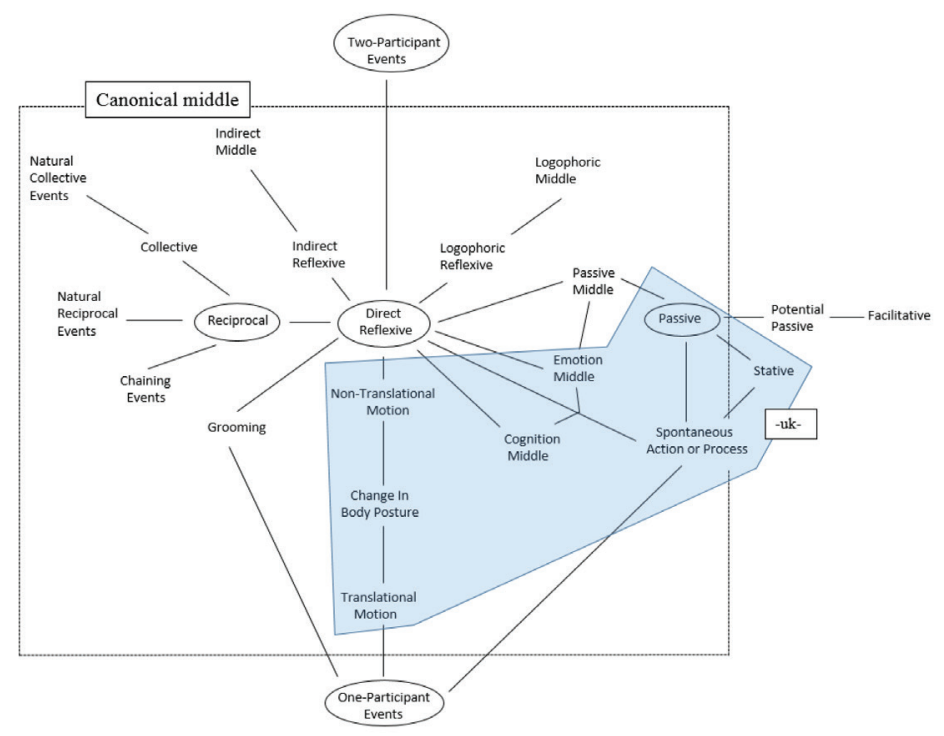

Figure 4. The cross-Bantu semantic range of separative intransitive *-øk- plotted on the semantic map of the middle domain (cf. Kemmer 1993)

between the semantic content of these suffixes within the semantic space of the middle domain can be attributed, at least partly, to the fact that *am- did not originally convey the notion of movement out of some original position (see \$2.2). Future comparative research on the functional domains of both suffixes in individual Bantu languages could shed more light on how they interact more specifically within the middle domain.

\subsection{The reflexive prefix}

Kemmer (1993) provides some examples of the reflexive marker -ti- in Changana (Mozambique) encoding middle situation types. Examples are shown in (1a), repeated here as (28).

$\begin{array}{ll}\text { Reflexive/middle -ti- } \\ \text { ku ti-tekela 'take for oneself' (p. 17) } & \text { [indirect middle/autobenefactive] } \\ \text { ku ti-milela 'germinate, sprout' (p. 19) } & \text { [spontaneous event] } \\ \text { ku ti-tsakela 'be(come) happy' (p. 21) } & \text { [emotive middle] } \\ \text { ku ti-nwaya 'scratch, rub oneself' (p. 61) } & \text { [bodily action middle] }\end{array}$

In a number of South-Western Bantu languages spoken mainly in Angola, the polyfunctionality of the reflexive not only extends to marking verbs denoting middle situation types, but also includes reciprocal derivation. Such is the case in Kwamashi, where the reflexive prefix $-c i$ - is used for both the reflexive (29a), middle situation types (29b) and reciprocal $(29 \mathrm{c})$. 
(29) Kwamashi (Zambia) (Bostoen 2010: 1-2)

a. Reflexive

-thaura 'scratch' > -ci-thaura 'scratch oneself'

-óa 'wash' > - cí-óa 'wash oneself'

b. Middle situation types

-cí-enga 'dress well, wear ornaments' [grooming]

-cí-neka 'stand on tiptoe' [change in body posture]

-cí-uba 'be at peace' [emotion]

c. Reciprocal

ka-tú-cí-mon-ine rero

$\mathrm{NEG}_{\mathrm{SP}}$-RECP-see-PRF today

'We haven't seen each other today.'

The historical associative suffix *-an-, the most commonly used suffix for reciprocity in Bantu, has lost its productive derivational function as a reciprocal marker in Kwamashi and is only retained in a number of lexicalized verbs denoting middle situation types, as shown in (30a). However, the reflexive-reciprocal polysemy has become so pervasive that $-c i$ - is now also used with verbs denoting naturally reciprocal events (30b).

(30) Kwamashi (Zambia) (Bostoen 2010: 3)

a. -hang-an-a 'meet'

-kan-an-a 'contradict, oppose'

-ngum-an-a 'assemble, gather'

$-k w a s h-a n-a$ 'lie flat'

-tand-an-a 'roll in pain'

-lyang-an-a 'be confused'

-mbutum-an-a 'muse'

b. -cí-andhipera 'quarrel'

-cí-cídha 'race, compete'

-cí-handa 'divorce'

-ci-hata 'be near to, neighbours with'

-cí-pitura 'look alike, be equal'

-cí-sinya 'barter, exchange'

In other languages where the reflexive is involved in reciprocal derivation, it is often combined with the associative. The latter can, however, not be used individually to denote reciprocity. In Songye, for example, reciprocal derivation is marked by a combination of the reflexive prefix - $i$ - and the suffix -een-, which is presumably a historical merger of the associative $\left({ }^{\circ}\right.$-an-) and applicative $\left({ }^{\circ}-i l-\right)$. This is illustrated in example (31).

(31) Songye (DR Congo) (Stappers 1964: 27)

$k u$-i-lek-éen- $a$ 'to leave each other'

$k u$-i-dil-éen-a 'to mourn each other'

$k u$-i-fut-éen- $a$ 'to pay each other'

$k u-i$-sep-éen-a 'to laugh at each other'

$k u-i$-ab-éen- $a$ 'to divide amongst each other'

ku-i-el-éen- $a$ 'to bombard each other' 


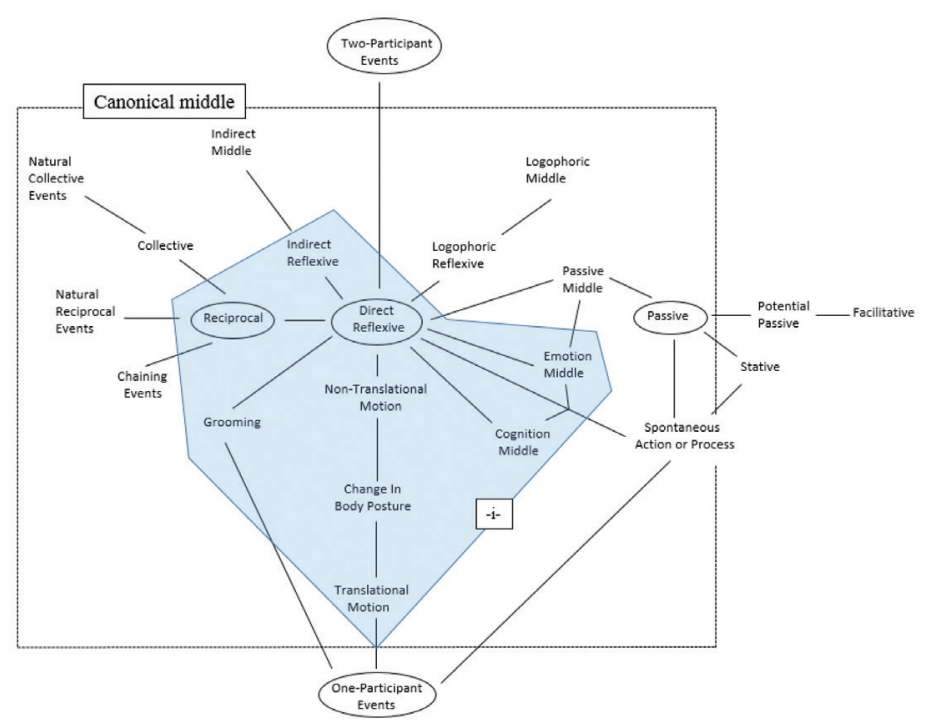

Figure 5. The cross-Bantu semantic range of the reflexive prefix*-(j)i- plotted on the semantic map of the middle domain (cf. Kemmer 1993)

In still other languages, such as Kaonde and Sanga (DR Congo), the reflexive and associative seem to be used in free variation as reciprocal markers (Bostoen 2010: 5). In Lunda, the associative has become largely lexicalized, but is still used as a reciprocal marker with a limited set of verbs next to the reflexive, which is the productive marker for reciprocity (Kawasha 2003: 325-326). Additional issues still remain to be studied and described in more detail, such as how these languages disambiguate reflexives with plural subject NPs and reciprocals. Hilde Gunnink (p.c.) reports that in Fwe (Zambia; Namibia), where reflexive-reciprocal polysemy is attested, the context and lexical semantics of the verb most often do not evoke ambiguity. However, if both a reciprocal and a reflexive reading would be available, speakers of Fwe can resolve the ambiguity by adding either omuntu nomuntu 'each other' or -eni 'self, owner'. Nevertheless, our main goal here is to point out that in certain Bantu languages, the reflexive prefix functions as a quasi-middle marker denoting additionally middle situation types and/or reciprocity. Figure 5 shows that the semantic space of the reflexive as a quasi-middle marker covers a number of middle concepts within the canonical middle domain. Very often these middle situation types are overlooked in Bantu grammar studies for the reflexive prefix.

\section{Middle voice in Bantu from a typological perspective}

The fact that a group of closely related functions is commonly denoted by a single verbal morpheme cross-linguistically and is often referred to as middle voice in traditional grammars has led Kemmer (1993: 24-26) to develop a typology of middle marking 
systems. Kemmer's typology, briefly outlined in (32), is based on the relationships between the reflexive and middle morphemes.

(32) Typology of middle marking systems according to Kemmer (1993)

a. One-form middle system

The middle marker is formally identical to the reflexive marker.

e.g. German: Er sieht sich 'He sees himself' (reflexive) vs. Er fürchtet sich 'He is afraid' (middle)

b. Two-form cognate system

The middle marker is similar, but not identical to, the reflexive, often being a shorter, i.e. phonologically "lighter", form of the "heavier" reflexive. The formal similarity is mostly due to a historical relation between the two.

e.g. Russian: Ivan uvidel sebja 'Ivan saw himself' ((heavy) reflexive) vs. On utomil-sja 'He got tired' ((light) middle)

c. Two-form non-cognate system

Middle marker is morphologically distinct from the reflexive marker.

e.g. Turkish: kendi- (reflexive marker) vs. -In- (middle marker)

Kemmer (1993) thus only considers a given morpheme to be a true middle marker if it is the sole marker of the middle voice within a language's verbal derivation system. We have therefore preferred to call the Bantu verbal morphemes discussed above 'quasi-middle' markers. Nevertheless, they still cover multiple grammatical categories and situation types that belong to the semantic domain of the middle. We could thus consider Bantu languages to be a fourth type within Kemmer's (1993) typology, namely a multiple-form system. In such a system, multiple verbal morphemes cover different parts of the canonical middle, yet sometimes conveying meanings situated on the periphery of the canonical middle domain. In most Bantu languages, the semantic space of the middle voice seems to be organized along two domains, which can be qualified as agent-oriented vs. patient-oriented functions. On the one hand, reflexes of the associative suffix *-an- (cf. §2.3) tend to be agent-oriented, although they have become unproductive and lexicalized in several present-day languages, thus paving the way to the quasi-middle in form of the reflexive-reciprocal polysemy (cf. §2.5). On the other hand, the neuter (\$2.1), the positional $(\$ 2.2)$ and the separative intransitive $(\$ 2.5)$ cover the patient-oriented part of the middle domain. Eventually, all three categories have the potential to develop into a variety of the quasi-middle that includes canonical passive use. It differs from language to language (group) as to which of the three - if any - ultimately undergoes this innovation. However, given the extremely low number of languages in which the neuter and the separative intransitive have become a dedicated passive marker compared to the larger area where the positional has taken over this derivation and, especially, taking into account numerous languages that have preserved the Proto-Bantu passive suffix, this particular categorial shift is, at best, only marginal. Nevertheless, these three suffixes can still be considered quasi-middles without a canonical passive function. 


\section{Conclusion}

Several polysemous Bantu verbal morphemes cover large parts of the functional domain which is generally considered the canonical middle voice. Although neither of them covers the majority of the subcategories subsumed under the canonical middle voice and therefore cannot be considered a 'canonical' middle, these morphemes divide up the semantic space of the middle voice into different smaller, but still multifunctional, semantic units. There seems to be a general distinction between morphemes whose semantics can be qualified as agent-oriented, such as the associative and reflexive, and others which exhibit patient-oriented semantics, such as the neuter, the intransitive separative and the positional. From a typological point of view, Bantu languages can therefore be categorised as languages with multiple-form middle systems. Future typological research should bear out whether other languages of the world have similar quasi-middle systems and uncover their typological features. As for future descriptive research on Bantu languages, it will be beneficial to consider these five verbal morphemes as quasi-middle markers. Bantu scholarship should push the semantic analysis of the verbal categories in question beyond the most common notions reconstructed to Proto-Bantu in order to obtain a more adequate, comprehensive and refined understanding of their rich polysemy.

\section{Acknowledgements}

We wish to thank Deo Kawalya (Ghent University - Makerere University) for the Luganda data, and the participants of the workshops 'Verbal derivation and verb extensions in Bantu' ( $6^{\text {th }}$ International Conference on Bantu Languages, Helsinki, 23 June 2016) and 'Correlations of valency-changing operations within and across languages' (46 $6^{\text {th }}$ Poznań Linguistic Meeting, Poznań, 15-16 September 2016) for their useful feedback.

\section{Abbreviations}

${ }_{1,2,3}$ - number of noun class; ${ }_{\text {I. II, III }}$ - demonstrative type; ASS - associative; AUG - augment; CL - nominal class marker; COP - copula; DEM - demonstrative; DISJ - disjoint; FV - final vowel; INAN - inanimate; INT - intensive; intr. - intransitive; IPFV - imperfective; NEG - negation; NP - noun phrase; NT - neuter; PASS - passive; PFV - perfective; PL - plural; PRF perfect; PRS - present; PST - past; RECP - reciprocal; SBJV - subjunctive; SEQ - sequential; SG - singular; SM - subject marker; TAM - tense-aspect-mood; tr. - transitive. 


\section{References}

Allan, Rutger. 2003. The middle voice in Ancient Greek: A study of polysemy. Amsterdam: J. Gieben.

Ambouroue, Odette. 2007. Éléments de description de l'orungu, langue bantu du Gabon (B11b). Brussels: Université Libre de Bruxelles. (Doctoral dissertation.)

Bastin, Yvonne \& Coupez, André \& Mumba, Evariste \& Schadeberg, Thilo C. (eds.). 2002. Bantu lexical reconstructions 3 / Reconstructions lexicales bantoues 3. Tervuren: Royal Museum for Central Africa. (http://linguistics.africamuseum.be/BLR3.html)

Bearth, Thomas. 2003. Syntax. In Nurse, Derek \& Philippson, Gérard (eds.), The Bantu languages, 121-142. New York: Routledge.

Bostoen, Koen. 2010. Reflexive-reciprocal polysemy in South-Western Bantu: Typology and origins. (Paper presented at Syntax of the World's Languages IV, Lyon, 23-26 September 2010.)

Bostoen, Koen \& Dom, Sebastian \& Segerer, Guillaume. 2015. The antipassive in Bantu. Linguistics 53(4). 731-772.

Bostoen, Koen \& Nzang-Bie, Yolande. 2010. On how "middle" plus "associative/reciprocal" became "passive" in the Bantu A70 languages. Linguistics 48(6). 1255-1307.

Bowler, Margit \& Gluckman, John. 2016. Expletive agreement, evidentiality, and modality in Logooli. (Paper presented at the 47th Annual Conference on African Linguistics, University of California, Berkeley, 23-26 March 2016.)

Chavula, Jean Josephine. 2016. Verbal derivation and valency in Citumbuka. (LOT 423). Utrecht: LOT.

Creissels, Denis. 2002. Valence verbale et voix en tswana. Bulletin de la Société de Linguistique de Paris 97(1). 371-426.

Culy, Christopher \& Fagan, Sarah M. B. 2001. The history of the middle in Dogon. Studies in African Linguistics 30(2). 171-194.

Dom, Sebastian. 2014. The neuter suffix in Bantu: A Systemic Functional Analysis. Ghent: Ghent University. (Master dissertation.)

Dom, Sebastian. 2015. The neuter suffix -ik- in Bantu. (Unpublished manuscript.)

Dubinsky, Stanley \& Simango, Silvester Ron. 1996. Passive and stative in Chichewa: Evidence for modular distinctions in grammar. Language 72(4). 749-781.

Fehderau, Harold W. 1962. Descriptive grammar of the Kituba language: A dialectal survey. Léopoldville: American Mennonite Brethren Board of Missions.

Grégoire, Claire. 2003. The Bantu languages of the forest. In Nurse, Derek \& Philippson, Gérard (eds.), The Bantu languages, 349-370. New York: Routledge.

Grestenberger, Laura. 2016. Reconstructing Proto-Indo-European deponents. Indo-European Linguistics 4. 98148. (http://booksandjournals.brillonline.com/docserver/journals/22125892/4/1/22125892_004_01_s004 text.pdf?expires $=1484054517 \& \mathrm{id}=\mathrm{id} \&$ accname $=$ guest $\&$ checksum $=0 \mathrm{~B} 9 \mathrm{CA} 70 \mathrm{D} 0428059 \mathrm{D} 1 \overline{\mathrm{FB}} 8 \mathrm{~A} 11 \mathrm{~F}-$ FA147D9F) (Accessed 10 January 2017.)

Guérois, Rozenn. 2015. A grammar of Cuwabo (Mozambique, Bantu P34). Lyon: Université Lumière Lyon 2. (Doctoral dissertation.)

Guérois, Rozenn \& Bostoen, Koen. 2016. From separative to middle/passive polysemy in Cuwabo (Bantu P34). (Paper presented at the 47th Annual Conference on African Linguistics, University of California, Berkeley, 23-26 March 2016.)

Helmlinger, Paul. 1972. Dictionnaire duala-français, suivi d'un lexique français-duala. Paris: Klincksieck.

Hulstaert, Gustaaf. 1957. Dictionnaire lomóngo-français (Annales - Série in- $8^{\circ}$ - Sciences de 1'Homme 16, Tome I). Tervuren: Musée Royal de l'Afrique Centrale.

Hulstaert, Gustaaf. 1965. Grammaire du lomóngo vol. 2: Morphologie (Annales - Série in- $8^{\circ}-$ Sciences Humaines 57). Tervuren: Musée Royal de l'Afrique Centrale.

Janic, Katarzyna. 2016. L'antipassif dans les langues accusatives (GRAMM-R. Études de Linguistique Française). Brussels: Peter Lang.

Janic, Katarzyna \& Segerer, Guillaume. 2011. Reciprocal-antipassive polysemy: Convergence from unrelated languages. (Paper presented at the Association for Linguistic Typology $9^{\text {th }}$ Biennial Conference, University of Hong Kong, Hong Kong, 21-24 July 2011.)

Jasanoff, Jay. 1978. Stative and middle in Indo-European (Innsbrucker Beiträge zur Sprachwissenschaft 23). Innsbruck: Institut für Sprachwissenschaft der Universität Innsbruck. 
Kabuta, Ngo Semzara. 2008. Nkòngamyakù Cilubà-Mfwàlànsa (Linguistic Series 19). Ghent: Ghent Research Centre of African Languages and Literatures, Ghent University.

Kawasha, Boniface Kaumba. 2003. Lunda grammar: A morphosyntactic and semantic analysis. Ann Arbor: University of Oregon. (Doctoral dissertation.)

Kazenin, Konstantin I. 2001. Verbal reflexives and the middle voice. In Haspelmath, Martin \& König, Ekkehard \& Oesterreicher, Wulf \& Raible, Wolfgang (eds.), Language typology and language universals: An international handbook vol. 2 (Handbooks of Linguistics and Communication Science 20). Berlin: Walter de Gruyter.

Kemmer, Suzanne. 1993. The middle voice (Typological Studies in Language 23). Amsterdam: John Benjamins.

Khumalo, Langa. 2009. The passive and stative constructions in Ndebele: A comparative analysis. Nordic Journal of African Studies 18(2). 154-174.

Kimenyi, Alexandre. 1988. Passives in Kinyarwanda. In Shibatani, Masayoshi (ed.), Passive and voice, 355386. Amsterdam: John Benjamins.

Kisilu Meso, Jean Samuel. 2001. Morphologie flexionnelle du kimboma. Kinshasa/Binza: Institut Pédagogique National. (Mémoire de licence.)

Kouarata, Guy Noël. 2015. Grammaire beembe: Langue bantu (H10) du Congo-Brazzaville. Paris: Edilivre.

Kulikov, Leonid. 2011. Passive to anticausative through impersonalization: The case of Vedic and Indo-European. In Malchukov, Andrej \& Siewierska, Anna (eds.), Impersonal constructions: A cross-linguistic perspective (Studies in Language Companion Series 124), 230-254. Amsterdam: John Benjamins.

Kulikov, Leonid. 2013. Middle and reflexive. In Luraghi, Silvia \& Parodi, Claudia (eds.), The Bloomsbury companion to syntax, 261-280. London: Bloomsbury.

Lichtenberk, Frantisek. 2000. Reciprocals without reflexives. In Frajzyngier, Zygmunt \& Curl, Traci S. (eds.), Reciprocals: Forms and functions, 31-62. Amsterdam: John Benjamins.

Marlo, Michael R. 2015. On the number of object markers in Bantu languages. Journal of African Languages and Linguistics 36(1). 1-65.

Meeussen, Achille Emille. 1967. Bantu grammatical reconstructions. Africana Linguistica 3. 79-122.

Meeuwis, Michael. 2010. A grammatical overview of Lingála. Munich: Lincom.

Morrison, Michelle Elizabeth. 2011. A reference grammar of Bena. Houston, Texas: Rice University. (Doctoral dissertation.)

Nagaya, Naonori. 2009. The middle voice in Tagalog. Journal of the Southeast Asian Linguistics Society 1. 159-187.

Nedjalkov, Vladimir P. 2007a. Overview of the research: Definitions of terms, framework, and related issues. In Nedjalkov, Vladimir P. (ed.), Reciprocal constructions. Vol. 1, 3-114. Amsterdam: John Benjamins.

Nedjalkov, Vladimir P. 2007b. Polysemy of reciprocal markers. In Nedjalkov, Vladimir P. (ed.), Reciprocal constructions. Vol. 1, 231-333. Amsterdam: John Benjamins.

Nurse, Derek. 2008. Tense and aspect in Bantu. Oxford: Oxford University Press.

Palancar, Enrique L. 2004. Middle voice in Otomi. International Journal of American Linguistics 70(1). 52-85.

Racine, Odile. 2015. Les extensions verbales en swahili standard (East African Languages and Dialects 24). Cologne: Rüdiger Köppe Verlag.

Schadeberg, Thilo C. 1982. Les suffixes verbaux séparatifs en bantou. Sprache und Geschichte in Afrika 4. 55-66.

Schadeberg, Thilo C. 2003. Derivation. In Nurse, Derek \& Philippson, Gérard (eds.), The Bantu languages, 71-89. New York: Routledge.

Seidl, Amanda \& Dimitriadis, Alexis. 2002. Statives and reciprocal morphology in Swahili. In Sauzet, Patrick \& Zribi-Hertz, Anne (eds.), Typologie des langues d'Afrique et universaux de la grammaire, 239-284. Paris: L'Harmattan.

Shibatani, Masayoshi. 2004. Voice. In Booij, Geert \& Lehmann, Christian \& Mugdan, Joachim \& Skopeteas, Stavros (eds.), Morphology: An international handbook on inflection and word-formation vol. 2 (Handbooks of Linguistics and Communication Science 14), 1145-1165. Berlin: Walter de Gruyter.

Stappers, Leo. 1964. Morfologie van het Songye. Tervuren: Musée Royal de l'Afrique Centrale. 